\title{
Research and assessment of the level of self- determination of the student's personality for future professional activity
}

\author{
Olga Shcherbakova ${ }^{1, *}$, Irina Sokolovskaya ${ }^{2}$, Andrey Chernykh $^{3}$, Venera Midova ${ }^{1}$ \\ ${ }^{1}$ Plekhanov Russian University of Economics, Moscow, Russia \\ ${ }^{2}$ State University of management, Moscow, Russia \\ ${ }^{3}$ Saint Petersburg Military Institute of the National Forces Guard of the Russian Federation, St. \\ Petersburg, Russia
}

\begin{abstract}
Presentation of research scientists towards the study of the development potential of the individual and her professional identity; provide a description of the various types of self-determination, justifies the common and what distinguishes professional and personal identity. The authors describe a complex of research and assessment of the level of professional orientation of students and undergraduates of Plekhanov Russian University of Economics. The authors presented the author's vision of 3 blocks of psychotechnologies: teaching, developing and information and communication, the use of which in the educational process of the University, will increase the level of their professional orientation and identity. The empirical part shows the selection, methods and procedure of the process of changing professional orientation and identity, as well as the procedure for processing the data obtained. The article also presents the results of a psychodiagnostic study of professional self-determination and professional identity in students of Economics, direction, students of technical orientation in the field of IT technologies, students of psychology: after conducting classes using various psychotechnologies-the results in the group of IT students have not changed much, most students have a pronounced status of "achieved professional identity"; most psychology students have become more understanding of their professional activitiesthey are characterized by the status of "moratorium"; the vast majority of Economics students have shown a formed professional identity and a high level of professional readiness.
\end{abstract}

\section{Introduction}

The research topic relevance is determined by the self-determination level of students of various specialties and the fact that every person, especially at the student age, has to find their place in life, choosing their own path, their future activities, shaping their future professional path. Currently the common situation is that future applicants do not understand what area of professional activity to go for, moreover, even when at University already, many

\footnotetext{
*Corresponding author: olga716@bk.ru
} 
of them can still not decide on the choice thay have already made. The problem of professional self-determination is particularly a hot topic nowadays. The world is constantly changing, new technologies are emerging, and together with them new professions appear and employers demands grow. It is also important to know and take into account professional self-determination peculiarities of students and graduate students studying in various programs.

\section{Research goals}

1. To study areas and methods of professional self-determination in the theory and practice of modern scientific research;

2. To organize and carry out empirical research of the students and graduate students selfdetermination level and its impact on their professional choice;

3. Perform comparative analysis of the professional identity results among students of economics, technical students in the IT technologies, and students of psychology.

\section{Research methods}

- theoretical analysis of literature on the problems of professional self-determination.

- students professional orientation survey, a method for revealing difficulties in selfidentification of junior students and their professional orientation, evaluating personal qualities necessary for professional occupation; assessment of communicative and organizational aptitudes during primary professional consultation (the method of communicative and organizational aptitude by V. V. Sinyavsky and B. A. Fedorishin); fivefactor personality questionnaire "The Big Five"; test based on professional self-determination study method by J. Marcia.

Professional self-determination involves individual development of a person, during which the process of profession selection and acquisition takes place; professional selfdetermination can be understood as a moment of personality formation, its adequate attitude towards the activity performed, personalization of this activity, and as a mechanism of personal maturity formation, implying the conscious choice of a person's place in the socialcultural environment.

The problem of personal potential development and self-determination has been the subject of research at various times:

- by psychologists who define the natural features of a person constructing the prerequisite for their specific abilities, orientation, attitudes, needs, abilities, talents development (A. Adler, B.G. Ananyev, L.S. Vygotsky, A. Maslow, S. L. S.L. Rubinstein, H. Heckhausen and others). The ideas of the role of potential in the personality (B. G. Ananyev, T. I. Artemieva, V.G. Aseev, V.P. Zinchenko, E. I. Isaev, K. Levin, V. N. Myasishchev, G. Allport, V. I. Slobodchikov, E. Fromm, M. Fuzon, etc.) and the concept of personal potential and its development (M. S. Kagan, M. V. Kolosova, V. N. Markov, I. O. Martynyuk, N. A. Nosov, V.G. Ryndak, Yu.V. Sinyagin, B. G. Yudin etc.) are worth mentioning.

- by teachers who consider it in the context of an individual educational path of educational goal-setting (E. V. Bondarevskaya, M. S. Kagan, V. V. Kraevskiy, V. G. Ryndak, E. G. Simonov, etc.).

The theoretical foundations of a young specialist self-identification problem and building a business career have been repeatedly considered in the papers of domestic and foreign scientists: D. Super, J. Holland, A. Maslow, E. Erickson, Sh. Fukuyama; in the studies of domestic authors: E. A. Klimova, E. F. Zeer, S. N. Chistyakova, N. S. Pryazhnikov, E. Yu. Pryazhnikova, S. V. Panina, L. S. Rumyantseva, E. A. Mogilevkina, M. V. Shcherbina, E. V. 
Kiseleva, etc. Business career building was studied by S. V. Shekshnya, F. R. Filippov, A. I. Kibanov, N.S. Pryazhnikov, A.A. Lobanov, E.A. Mogilevkin and many others.

The theoretical basis of this research comprise the surveys of E. A. Klimov [1], Rebecca Ponce de Leon, Aaron C Kay [2] and E. Erikson [3].

There is a general definition commonly used in a modern society: self-determination is both a process and the outcome of a person's choice of their position, goals and means of existence in certain life circumstances [4].

Professional and personal self-determination have a lot in common, and in their highest manifestations they are almost similar. In the effort to pull them apart, the two fundamental differences are found $(5,6,7)$ :

1) professional self-identification is more specific, easier to manifest officially (get a diploma, etc.); personal self-identification is a more complex process ("a personality diploma, at least for mentally healthy people, is not issued yet");

2) professional self-determination depends more on external (favorable) conditions, while personal self-determination depends on a person, moreover, often unfavorable conditions provide people with opportunity to prove their personality in earnest (heroes appear in critical times).

Based on the studied theoretical material on the problem of professional selfdetermination and professional identity formation, it becomes obvious that this problem is relevant and requires a solution.

\section{Results}

At the first stage of the experimental work, a psychodiagnostic study of junior students was arranged and conducted using the author's questionnaire for identifying the key selfdetermination difficulties during educational process at Plekhanov Russian University of Economics (PRUE) and the author's questionnaire "How I see myself in the profession", for identifying their problems in professional development. The results of the research performed with the methods allowing to see the level of PRUE students and graduate students selfdetermination are given below.

Figure 1 shows the average indicated values of self-determination level difficulties of Junior students.

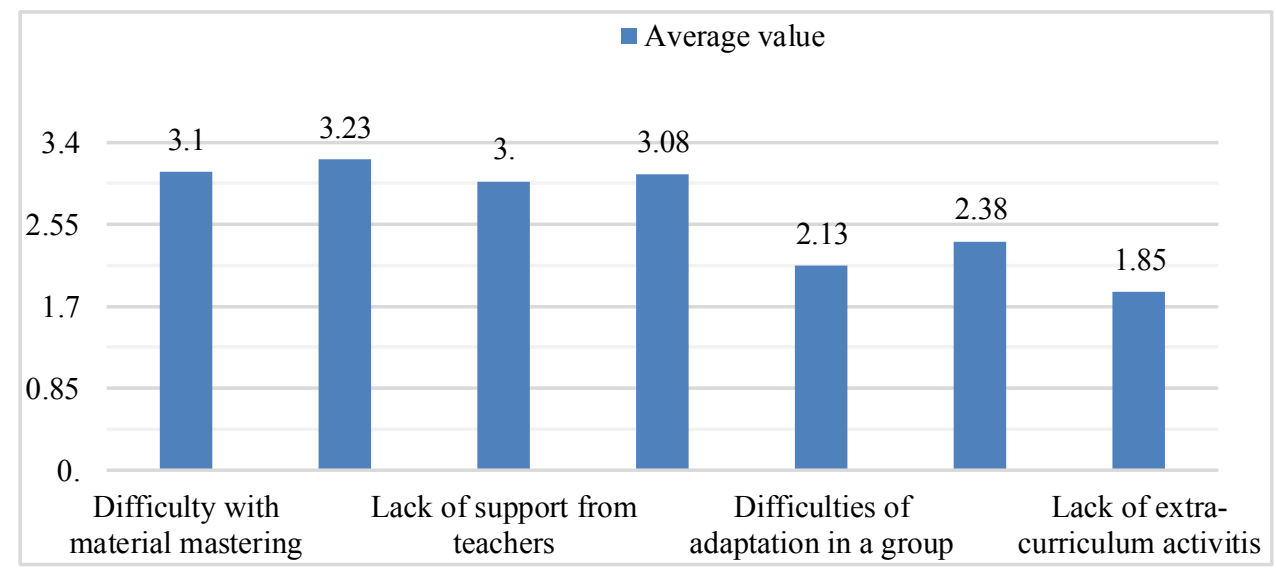

Fig. 1. Average indicated values of self-determination level difficulties of Junior students.

As can be seen from Figure 1, the difficulty associated with a high study load has the biggest value. The difficulty in mastering the material is the next one, which indicates that 
students find the subjects studied quite difficult. The third greatest difficulty is the lack of a clear relationship between current studies and future professional occupation. Finally, the lack of teachers support rounds out the "difficulty rating", which means that students do not feel the participation and interest of teachers in them as individuals and participants of the educational process.

Students also indicated in their responses the qualities of their character that hinder their future professional development - quick temper (47\%); self-doubt (33\%) and laziness $(20 \%)$. Respondents pointed out the following factors that had an influence on their choice of future professional occupation most of all: abilities (30\%); parents/relatives and life circumstances $(25 \%)$.

The surveyed students rated the following qualities of the character as the most important: patience, perseverance and ability to communicate with people, which shows the nervous system instability of most students. There are also problems with the communication skills associated with frequent communication on the Internet and lack of the personal contact.

The results of students' and graduate students' communication and organizational skills assessment according to the method of communicative and organizational aptitude by $\mathrm{V}$. V. Sinyavsky and B. A. Fedorishin are presented below.

Figure 2 shows the distribution of students and graduate students by levels of communication and organizational aptitude.

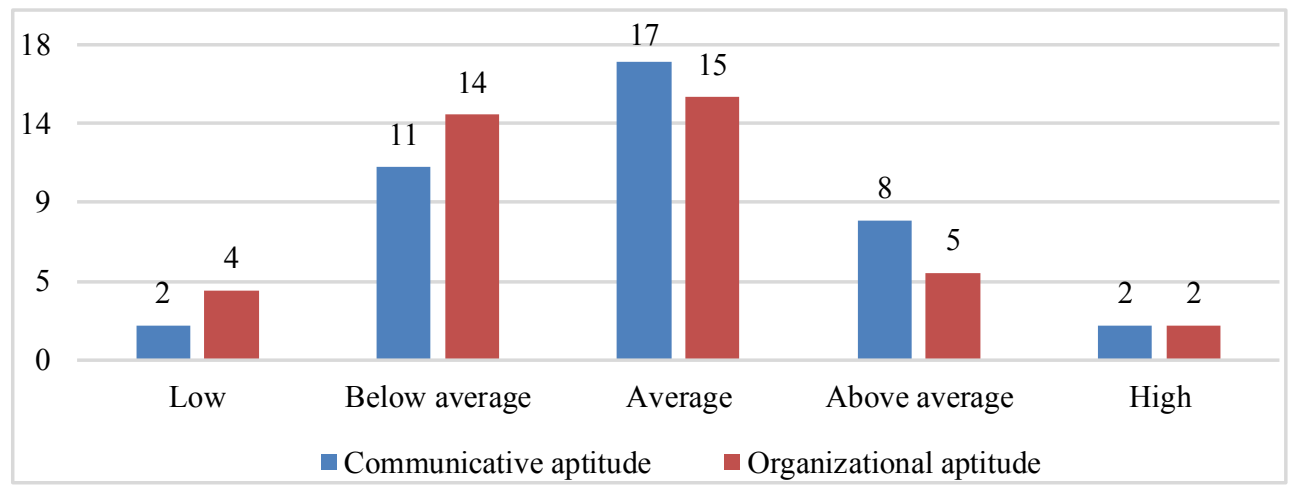

Fig. 2. Distribution of students and graduate students by levels of communication and organizational aptitude.

As seen from Figure 2, most students and graduate students demonstrate an average level of both communication and organizational aptitude, but their aptitude potential is not very stable. This test group needs further serious and systematic work on the formation and development of communicative and organizational inclinations.

According to psychological research and data of surveys conducted among PRUE students and graduate students, certain personal qualities of students are important for choosing a profession and future effective professional self-realization. Figure 3 shows the average values of indicators for the "The Big Five" methodology. 


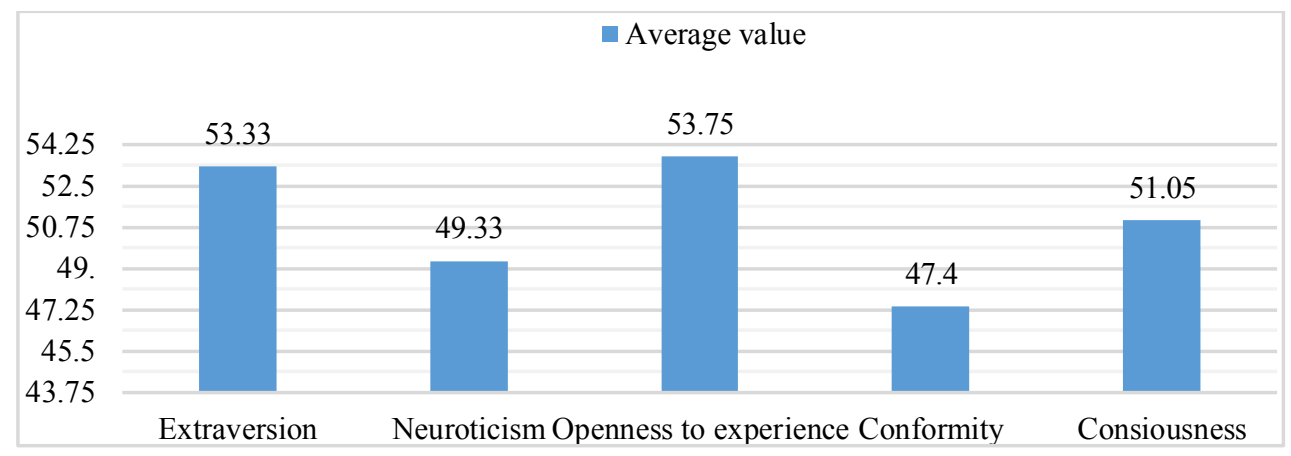

Fig. 3. Average indicated values of personal qualities of students and graduate students according to the "The Big Five" method.

The results of the analysis using "The Big five" method showed the necessity to pay attention to the students' emotional state and to develop a psychotechnological complex for students psycho-emotional sphere development.

Professional self-determination level is closely related to a professional identity, the structure of which includes the following statuses: accomplished identity, moratorium, premature identity, diffuse identity.

To carry out research using the J. Marcia method 245 PRUE students of various specialities were selected. The economic and IT spheres were selected due to their priority at Plekhanov Russian University of Economics. Psychological spheres were selected as representing two opposite professional types of activities: human-to-human and human-tosign-system.

The study was conducted in several stages. Stage 1 of the empirical research included a primary diagnosis of professional orientation maturity and consideration of each students' group results; the 2nd stage of the empirical research comprised training using the psychotechnological complex; stage 3 consisted of professional self-determination level

To develop the students and graduate students professional orientation, we have created a complex of psychotechnologies, consisting of three main blocks: training psychotechnologies; developing psychotechnologies; information and communication psychotechnologies. [8]

\subsection{Cluster 1 - training psychotechnologies}

One of the most effective forms of information assimilation is gaming psychotechnologies, which involve playing the most common professional situations and personal engagement of participants in simulated situations; project activity technology is a specially organized independent educational activity of students under the teacher's supervision to solve their meaningful problem. Psychotechnology of project activity develops intellectual and creative potential, independence, and contributes to successful socialization of a person.

\subsection{Cluster 2 - psychotechnologies of developmental training}

The main goal of developmental training is to develop thinking and analytical abilities, so that the student can use their inherent potential. [9]

The cluster of developmental psychotechnologies comprises: case study technology; critical thinking psychotechnology; dynamic thinking psychotechnology. $[10,11,12]$

\subsection{Cluster 3 - information and communication technologies}


New information and communication psychotechnologies open up completely new learning approaches related to the unique capabilities of modern computers and telecommunications. $[13 ; 14]$

New information technologies include digital technologies in education. Communication psychotechnologies include: Active listening, I-statements, NLP technology (neurolinguistic programming). [15]

This complex of psychotechnologies was tested at Plekhanov Russian University of economics with undergraduate students of technical, economic and psychological specialties during the classes in Psychology and Psychology of Conflict Resolution; and within Master's programs in the subjects of Psychology of Conflict Management in Business, Economic Psychology, Consumer Psychology and Leadership. It is aimed at improving students' professional training and professional self-identification.

\section{Discussion}

In order to confirm the psychotechnologies effectiveness for the development of students' self-realization, the results of an experimental study before the use of training and developmental psychotechnologies and after their use were examined.

To begin with, the extent of self-realization difficulties before and after using various psychotechnologies in training were compared. Figure 4 shows the average indicated values of students' self-realization difficulties before and after the educational experiment.

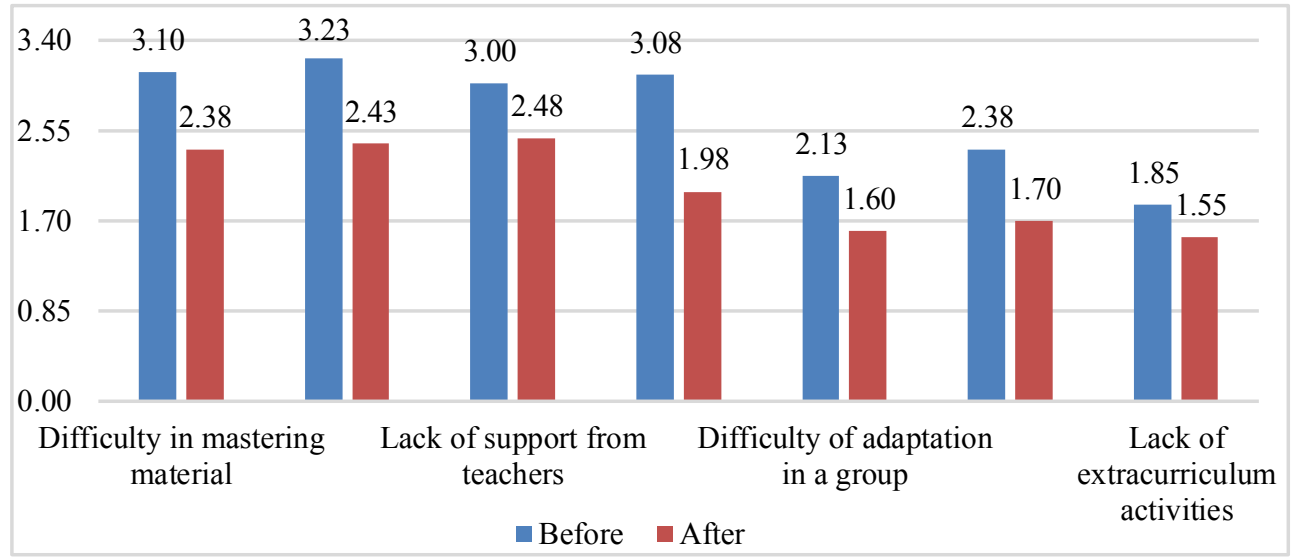

Figure 4. Average indicated values of self-realization difficulties of Junior students before and after the educational experiment.

As seen in figure 4, all difficulties in students' self-realization show a noticeable decrease.

Furthermore, changes in students' communication and organizational skills were considered. Figure 5 shows the average indicated values of communicative and organizational aptitudes before and after the educational experiment. 


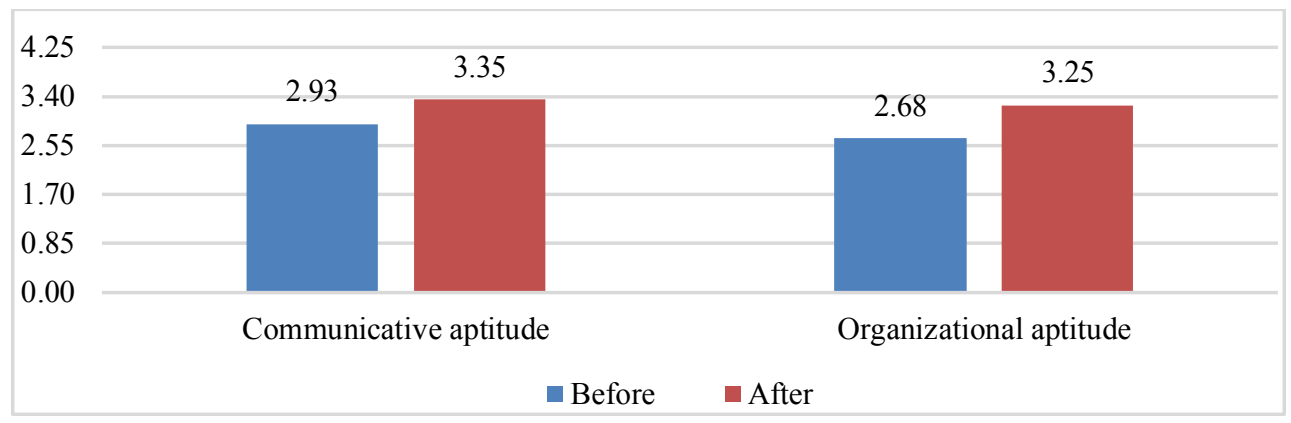

Fig. 5. Average indicated values of students' communicative and organizational aptitudes before and after the educational experiment.

As can be seen from Fig. 5, the level of communication and organizational aptitudes development increased significantly after the application of a psychotechnologies complex in study during practical classes compared to what it was at the time of initial diagnostic assessment.

Thus, the check-up test suggests that the complex of psychotechnologies developed by the authors for the students and graduate students self-realization developement is effective and successful. Students have experienced fewer difficulties in self-realization, they developed such skills and personal qualities as autonomy, system reflection, communicative and organizational aptitudes, purposefulness and responsibility.

After testing psychotechnologies in the educational process for the professional orientation development in students of economic profile, the following results were obtained using the method of J. Marcia:

1. the number of students who have formed a professional identity has increased. The number of students with the status of moratorium and with the status of diffused professional identity has decreased. There are no students with the status of premature identity. It can be concluded that students developed a better understanding of the scope of their future occupational activities, and the existing ideas about professional activities have expanded.

2. the test subjects can be divided into two groups. The first group includes students who have the greatest expression of such types of professional identity as diffused and premature. When choosing a profession, these subjects were guided not by their own preferences and interests, but by a random decision or opinion of others. Fairly low level of professional determination is typical for them.

The second group includes test subjects of a mature identity or a moratorium. A higher level of professional identity expression than in the first group representatives is observed here. These students have a more conscious approach to choosing a profession and have a clearer idea about it. The level of professional determination of these test subjects reaches a higher value.

After having classes with the described psychotechnologies, the results in the group of IT students did not change much.

Students who come to get education in the field of IT technologies have a good understanding of their future professional activities. Moreover, these students are supposedly much better oriented in the frame of relations "human-to-sign-system", while the indicated psychotechnologies are focused mainly on students of the "human-to-human" and "humanto-business" frames.

The lowest rating was shown on a diffused identity scale. It is pronounced only in $4 \%$ of the total number of test subjects in this group.

The majority of psychology students are seen to grow more understanding of their professional occupation. 
In addition, the desire for reflection among students of psychology have become more typical. They are more likely than the other students to think about their own personal characteristics and personal development.

The results of the research show that IT students have the expressed status of "accomplished professional identity", suggesting that they have mature professional self identification. This is due to the fact that they clearly understand what IT specialists will do and try to create their own product, engaging themselves directly in professional activities. This trend is shown in the summary Figure 6.

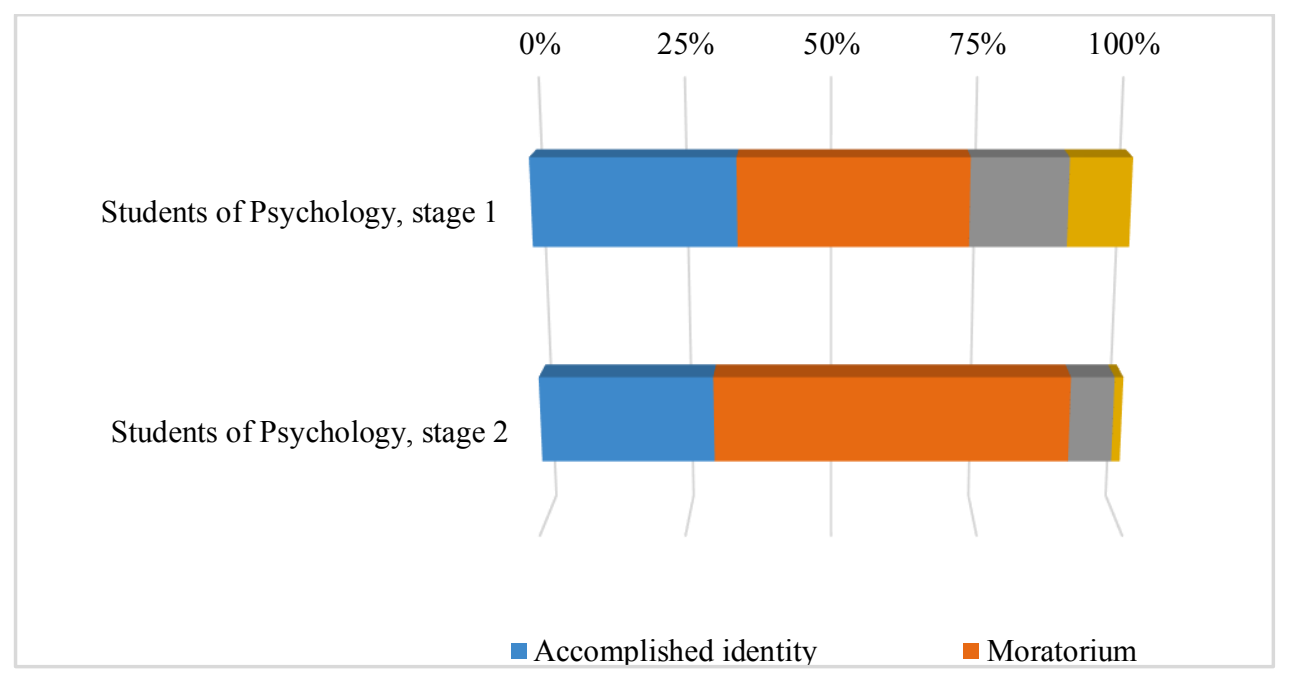

Fig. 6. Dynamics of professional identity statuses.

\section{Conclusions}

Analysis of the empirical findings showed that:

1. Most students entering higher educational institutions do not fully understand the scope of their future professional occupation. While preparing for future professional activities, students pay more attention to the problem of communication. The highest priority of their life is to be a creative person and live a healthy lifestyle.

2. Students and graduate students have difficulties associated with a high study load. This includes the number of subjects studied and the requirements set for them; difficulties in mastering the material and the lack of a clear relationship between current studies and future professional occupation.

3. Students indicate qualities of their character that hinder their professional development - quick temper (47\%); self-doubt (33\%) and laziness (20\%). The surveyed students rated the following qualities of the character as the most important: patience, perseverance and ability to communicate with people, which shows the nervous system instability of most students.

4. Most students and graduate students demonstrate an average level of both communicative and organizational aptitude, and a significant number of students and graduate students have a communication and organizational skills level below average.

5. Analysis of the results using "The Big Five" methodology showed that mostly students and graduate students have an average level of such qualities development as: extroversion, respect for others and desire for cooperation, consciousness and responsibility, but it is necessary to pay attention to the emotional state of students. A moderate indicating value of neuroticism suggests the relative emotional stability of the respondents. 
6. The selected J.Marcia's method of "professional identity study" ensured the comprehensive examination level of professional self-determination of the student's personality.

7. The presented 3 clusters of psychotechnologies were tested in the educational process at Plekhanov Russian University of Economics, at the Faculty of Hotel, Restaurant, Tourism and Sport Industry, Faculty of Economics and Law, Management Faculty and Faculty "Institute of Digital Economics and Information Technologies".

As the results of surveys, questionnaires and professional self-determination formation methods showed, the classes conducted with the use of a psychotechnologies complex form a clearer idea of the future professional activity. The proposed complex of psychotechnologies successfully works in the system of education in the "human-to-human" and "human-to-business" spheres, which include Economics and Psychology specialties. There is a need to further develop psychotechnologies aimed at the self-determination formation in the "human-to-sign-system" frame, which includes the sphere of IT technologies.

\section{Summary}

Professional self-determination is a complex process of development a person's attitude to the profession and a way of their self-realization.

In order to understand what students and graduate students think about their future profession, about their professional qualities, a comprehensive study and assessment of the students' self-determination level was arranged, as well as a psychotechnologies complex was created and tested, helping to effectively prepare the students for future professional occupation and to study the students' self-determination level.

Based on the empirical findings, we have identified professionally important personal qualities that students need in their professional occupation. These qualities include: thinking operations of analysis, dynamics of thinking, self-confidence, agility of communication, organizational abilities, ability to control the emotional-volitional sphere.

Analysis of the findings on a sample of more than 300 people showed that the real psychological profile of the graduate is far from the requirements of employers. There is a need to conduct psychological testing and surveys to determine the applicant's suitability for the profession not only when he/she applies for a job, but perhaps also when he/she applies to University.

To increase the level of professional competence maturity of PRUE students and graduate students, the purposeful use of a psychotechnologies complex in the educational process is needed.

The following peculiarities of the professional self-identification process were revealed for the students studying Psychology and Economics, as well as for the technical students who participated in the experimental research:

-For psychology students, the "moratorium" status is more typical, i.e. the desire to know oneself for successful professional activity, which is most characteristic for the students who try on various professions and specialties for further employment and life.

-The vast majority of students-economists have a well-formed professional identity and a high level of professional readiness. Talking about professional sphere, in these students the "human-to-business" frame prevails, which is quite consistent with the description of the economist's profession, since it involves drawing up real plans, large projects, and participation in cases with a financial risk.

-A significant part of students-programmers manifested the accomplished identity. This is most likely due to the specifics of their choice of profession and education, since programmers have better understanding of their profession and future responsibilities in the 
workplace. Also, the "human-to-sign-system" frame prevails in IT students, which corresponds to their chosen profession, because a good level of orientation in symbols and language systems is necessary.

\section{Reference}

1. D.P. Zavodchikov, P.O. Maniakova, Education and science 20(1), 116-135 (2018) DOI: 10.17853/1994-5639-2018-1-116-135

2. R. Ponce de Leon, A.C. Kay, Current Opinion in Behavioral Sciences 34, 112-117 (2020) https://doi.org/10.1016/j.cobeha.2020.02.013

3. I.V. Lysak, Bulletin of Tomsk state University. Philosophy. Sociology. Political science 38, 130-138 (2017) DOI: 10.17223/1998863y/38/

4. S. Bogomaz, N. Kozlova, I. Atamanova, Procedia - Social and Behavioral Sciences 2145, 552-558 (2015) doi: 10.1016/j.sbspro.2015.11.759

5. E. Valitova, V. Starodubtsev, L. Goryanova, Procedia - Social and Behavioral Sciences 2145, 739-747 (2015) doi: 10.1016/j.sbspro.2015.11.706

6. N. Shmurygina, N. Bazhenova, R. Bazhenov, N. Nikolaeva, Procedia - Social and Behavioral Sciences 2145, 95-102 (2015) doi: 10.1016/j.sbspro.2015.11.599

7. N.S. Pryazhnikov, National Psychological Journal 3(27), 144-150 (2017) DOI: 10.11621/npj.2017.0316

8. Yu.R. Varlakova, Bulletin of Tomsk state pedagogical University, 87-89 (2017) doi: 10.23951/1609-624X -2017-8-87-90

9. M.Yu. Chernyshev, A.M. Zhuravleva, Integration of education 20(1), 37-49 (2016) doi: 10.15507/1991-9468.082.020.201601.037-050

10. E.N. Galushina, M.S. Apanovich, P.V. Galushin, Scientific Bulletin. Humanities series 38(2), 314-320 (2019) doi:10.18413/2075-4574-2019-38-2-314-320

11. A.A. Grekova, Bulletin Of SUSU. "Psychology" Series 12(1), 28-38 (2019) doi: 10.14529/psy190103

12. Yu.A. Filonova, Yaroslavl pedagogical Bulletin 6(105), 108-114(2018) DOI 10.24411/1813-145X-2018-10233

13. Z.A. Kireenkova, Servicing in Russia and abroad 2(58).9, 76-87 (2015) Doi: $10.12737 / 11893$

14. E. Liliana Danciu, Procedia - Social and Behavioral Sciences 30, 2204-2209 (2011) doi:10.1016/j.sbspro.2011.10.429

15. V.P. Gustyakhina, L.V. Popova, TSPU Bulletin 8(197), 149-154 (2018) DOI: 10.23951/1609-624X-2018-8-149-154 